\title{
COMPRESSION IGNITION ENGINE FUELLING WITH GRAPHENE DOPED DIESEL-HYBRIDE BIODIESEL BLEND: PERFORMANCE ANALYSIS
}

\author{
SATISH L HULAMANI, MAHESH A KAMOJI \& PRASAD G HEGDE \\ ${ }^{I}$ Department of Mechanical Engineering, KLE Dr. M S Sheshgiri College of Engineering and Technology,
} Belagavi, Karnataka, India

\begin{abstract}
In response to climate change dictating the reduction of carbon footprint, the potential of rotten coconut oil as a potential diesel blend has been explored. The choice of rotten coconut oil steers clear of the food and fuel competition. With the principle aim of no frame power loss a blend of Cotton seed oil and rotten Coconut oil in $10 \%$ by volume each and Diesel by volume of $80 \%$ is created which ensures that on volume basis the lower calorific value suffers no loss. A compression ignition engine is operated with three fuels, Diesel, Blend and Blend with Graphene at constant speed of 1500 RPM and at three injection pressures of 175 bar, 200 bar and 225 bar. It is observed that at 175 bar injection pressure, a near $10 \%$ increase in specific fuel consumption is seen to completely neutralized by adding Graphene and the baseline Diesel performance is restored. At 225 bar pressure, engine specific fuel consumption seems to improve by about 5\% on shifting from Diesel to blend which on adding Graphene results in near $10 \%$ improvement over baseline Diesel performance. Graphene seems to provide a clear improvement for the blended fuel to realize neat Diesel performance.
\end{abstract}

KEYWORDS: Bio-Oil Blend, Nano Additives, Graphene, Frame Potential Recovery \& Carbon Foot Print

Received: Jun 10, 2020; Accepted: Jun 30, 2020; Published: Jul 16, 2020; Paper Id.: IJMPERDJUN2020351

\subsection{INTRODUCTION}

Climate change induced by unrestrained use of fossilized carbon based resources has attained critical proportions, potentially to the point of no return. Model based predictions indicate that if the fossil fuel use continues in the business as usual scenario, by the year 2100, earth would warm up anywhere between 5 and 8 deg Cover the preindustrial revolution era average [1]. One extreme hypothesis argues that not only complete fossilized fuel displacement is mandatory but sequestration of the $\mathrm{CO}_{2}$ present in the atmosphere is also essential to limit the temperature rise to $1.5 \mathrm{deg} \mathrm{C}$. Among a range of options being explored to offset fossilized carbon based fuels, use of second generation bio-derived alternatives is at the forefront for displacement of fossilized hydrocarbons. In respect of compression ignition engines, oils extracted from seeds/balks of vegetation and subsequently transesterified, commonly designated as bio-oils are the most commonly used resources. In respect of bio-oils, one of the key factors that requires attention corresponds to the fact that with food-fuel debate clearly ruling out the use of edible resources for fuel purpose, a range of locally available resources are being considered for generating biooils. In this context, one of the key contributor is from waste and/or biologically degrading edible resources which may no longer have utility as food. While literature indicates limited work in this direction, the potential is immense with substantial amount of oil based food getting degraded due to variety of purposes.

One of the critical challenges in respect of using bio-derived alternatives corresponds to the general loss 
of engine performance due to variations in the thermo-physical and transport properties (calorific value and viscosity being two critical parameters) of such bio-fuels in comparison with baseline Diesel [2].As such, a range of scientific efforts are currently underway towards minimizing the performance loss of the engines on fuelling with Bio-Oils (either as neat fuel or as blend).One of the approaches being considered corresponds to intervention on the engine frame with charged operation of the engine (requiring turbocharging of the engine if naturally aspirated OR pressure ratio boosting if already turbocharged) with the principle intention of rating recovery/boost for a given frame (kW per litre of swept volume). The other, more straightforward approach corresponds to intervention on the fuel side with attempts to improve the fuel characteristics. A range of additives like $\mathrm{Al}, \mathrm{Mg}, \mathrm{Zr}, \mathrm{Ti}, \mathrm{Ni}$, boron (a metalloid), and metal oxidestypically of nano size are being explored [3]. It is reported that careful choice of metallicadditives and carbon nanotubes can significantly reducing ignition delay and while also ensuring cleaner combustion. The additives are known to act as a catalyst in the combustion zone leading to cleaner combustion.

The current work, under the overarching philosophy of using biodegrading matter uses a mixture of oil derived from rotten coconut and coconut seed oil in equal proportions and blended with Diesel for analysing the performance of a compression ignition engine. Graphene [4] is used as an additive to explore the possibility of realizing performance improvement over the baseline blend performance.The choice of Graphene over typical metal based additives is primarily owing to the high mechanical strength and unique electronic properties, high thermal conductivity, high surface area, extraordinary electro-catalytic activities and excellent mobility of charge carriers which makes it a wonderful support media for transporting radicals in the combustion media. These properties make Graphine an ideal additive that can potentially boost combustion characteristics in a CI engine. Leveraging the properties of Graphene, the emphasis in the current investigation is primarily on the general performance of the engine in terms of specific fuel consumption and in-cylinder response in terms of pressure crank angle and heat release data. This preliminary investigation is set to provide the basis for a more elaborate plan of action for using biodegrading resources for deriving oils.

\subsection{LITERATURE REVIEW}

The review of literature has exclusively focused on references to adopting additives for improving the performance of Diesel-Bio Oil blends in CI engines. While literature is replete with references to analysis of performance of CI engines with additives in Blends, for brevity, a few of the most recent, critical literature reporting on the use of Graphine are highlighted in the current article.

In an important work addressing the influence of Graphene from the perspective of material science Rasheedet. al., [5] have reported on the heat transfer and tribological performance of Graphene Nanolubricant in 4-stroke IC engineering. The addition of $0.01 \mathrm{wt} \%$ graphene results in $23 \%$ enhancement in thermal conductivity (k) at $80{ }^{\circ} \mathrm{C}$, and $21 \%$ reduction in the coefficient of friction $(\mu)$. Moreover, $70 \%$ enhancement in heat transfer rate of the engine is also achieved in the presence of graphene. SEM images of the piston rings collected after $100 \mathrm{~h}$ of engine operation show that the oil containing graphene $(12 \mathrm{~nm})$ decreases the piston wear compared to base oil without graphene.Principally this article kind of lays the foundation for overcoming some of the critical challenges experience in respect of CI engine operation with blended fuels. Extending the analysis to actual performance of the engine, the first literature addressed is the DieselEthanol blend, one of the most common blend.Heidari-Maleni, A., et. al., [6] have investigated the influence of Graphene quantum dot (GQD) nano-particles on ethanol-biodiesel blend fuelled CI engines. For a 10\% by volume blend, GQD nano-particles with concentration of $30 \mathrm{ppm}$ were considered. The addition of nano particles to the fuel increased power 
and torque by $28.18 \%$ and $12.42 \%$ respectively, and reduced SFC, CO and UHC by $14.35 \%, 29.54 \%$ and $31.12 \%$ respectively, compared to neat Diesel.The realization of such high improvements is rather surprising. Paramashivaiah, B. M., et. al., [7] have reporrted on the effect of graphene nanoparticles addition in different levels with simarouba biodiesel and diesel blends on performance, combustion and emission characteristics of CI engine. They report that in dispersing graphene in Simarouba methyl ester (SME) blend with diesel improvement in brake thermal efficiency by $9.14 \%$, reduction in unburnt hydrocarbon $(\mathrm{HC})$ by $15.38 \%$, carbon monoxide (CO) by 42.855 and oxides of nitrogen (NOx) emission by $12.71 \%$ with is observed. It is also reported that the addition of graphene nanoparticles has resulted in a significant reduction in the combustion duration and a marginal increase in peak cylinder pressure at all operational loads.In a Graphene oxide content parametric analysis, Hoseini, S. S., et. al., [8] have blended B20 (standard nomenclature) with 30, 60, and 90 ppm of Graphene. It has been reported that by using GO, power and EGT significantly increase. Furthermore, by using GO nano-particles, significant reductions in CO ( 5\%-22\%) and UHCs $(\sim 17 \%-26 \%)$ were observed. In another interesting investigation of using bio-oil derived from dairy scum oil, Soudagar, at. al., [9] have used Sodium dodecyl sulfate (SDS) as a surfactant for uniform dispersion of graphene oxide nanoparticles in the fuel blends. The dispersion and homogeneity were characterized by ultraviolet-visible spectrometry. For the Graphene blended fuel, notable improvement in the performance and emissions characteristics has been reported. The brake thermal efficiency improved by $11.56 \%$, a reduction in brake specific fuel consumption by $8.34 \%$, unburnt hydrocarbon by $21.68 \%$, smoke by $24.88 \%$, carbon monoxide by $38.662 \%$ for the nanofuel blend DSOME2040 and oxides of nitrogen emission by $5.62 \%$ for fuel DSOME(B20). In regads to in-cylinder combustion, a reduction in the combustion duration, ignition delay period and improvement in the peak pressure and heat release rate at maximum load condition has been reported.

The principle take away from the presented literature review is that Graphene seems to have a significant positive influenceon the general performance of CI engine with varying degree of improvement reported for both specific fuel consumption and emissions. The other key takeaway is that attempts at using hybrid bio-fuel blends seem to be extremely limited, and particularly there seem to be no attempts at using cottonseed oil and rotten coconut oil blend. As such, the review of literature provides a clear pathway for analysing the influence of Graphene on Diesel-Hybrid bio-oil blend.

\subsection{MATERIALS AND METHODS}

The current work is primarily directed at investigating the influence of Graphene as an additive to Diesel - Bio Diesel blend towards exploring the potential of performance recovery of the baseline Diesel engine when operated with blends. Towards this end, considering that rotting coconut oil was decided to be used as one of the key ingredients, a range of bio-diesels were evaluated to check for property similarity with bio-oil derived from rotten coconut oil. It was observed that bio-oil derived from cotton seed has property very close to that to rotten coconut oil. The trans-esterification facility for the generation of bio-fuel from desired feed is shown in figure 1 (a). Considering the similarity in properties, a blend of Diesel with an equal portion of Rotten Coconut Oil and Cotton Seed Oil was created using the continuous stirring method.Considering that the initial research was towards exploring the potential for performance improvement, a volume blend of $80 \%$ Diesel and $20 \%$ Bio-oil (equal mixture) was decided to be used for analysis. Towards understanding the potential influence of Graphene, 50 milligrams of Graphene is added to one litre 80-20 blend. The choice of $50 \mathrm{mg} / \mathrm{l}$ is based on the report by EL-Seesyet. al., [10] wherein in investigating the impact of adding Graphene Oxide to neat 
Jatropha Methyl Ester on a single cylinder air cooled direct injection four stroke diesel engine, it is reported thatconcentration of $50 \mathrm{mg} / \mathrm{L}$ had the optimum improvement in the overall characteristics of engine performance and emissions.

\subsection{Engine Specifications}

A single cylinder four stroke air cooled high speed Diesel engine is used for the analysis. The engine is rated at $3.5 \mathrm{kWe}$ at $1500 \mathrm{RPM}$ on normal Diesel engine with $45 \mathrm{MK} / \mathrm{kg}$ calorific value and has a rugged in-cylinder pressure measurement systemfor the measurement of absolute in-cylinder pressure as a function of crank angle. The engine test rig is presented in figure 1 (b) as below.
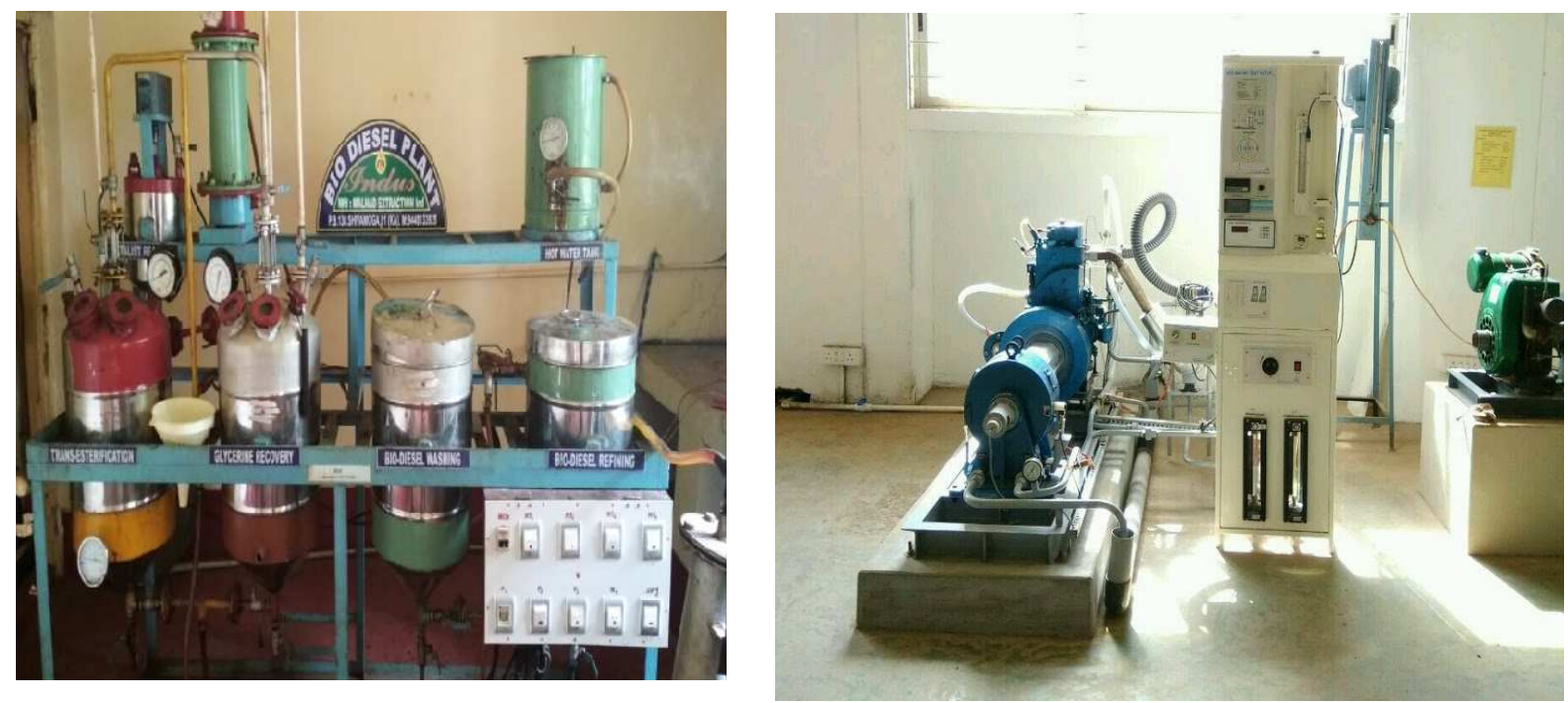

Figure 1: (a) Infrastructure for Trans-Esterification and (b) CI Engine Test Rig with in-Cylinder Pressure Measurement Facility.

\subsection{Fuel}

With the principle focus of the current work being investigating the influence of Graphene on Diesel-BioOil blend, a blend of Cotton seed oil and rotten Coconut oil in $10 \%$ by volume each and Diesel by volume of $80 \%$ is created. The blend is designated as B20 to indicate $20 \%$ by volume bio-oil.The choice of rotten Coconut oil and cotton seed oil is primarily due to their similar calorific value and density. Table 1 compares the heating value of the fuels on both mass and volume basis.

Table 1: Density and LCV of Neat Biofuels, Diesel and Blend (20-80)

\begin{tabular}{|l|c|c|c|c|c|c|} 
& Units & Diesel & Cotton SO & Rotten CO & Blend & Diff \% \\
\hline $\mathrm{LCV}$ & $\mathrm{MJ} / \mathrm{kg}$ & 44.0 & 39.6 & 39.9 & 43.1 & 2.05 \\
\hline Density & $\mathrm{Kg} / \mathrm{m}^{3}$ & 832.0 & 921.5 & 919.8 & 849.6 & -2.01 \\
\hline $\mathrm{LCV}$ & $\mathrm{MJ} / \mathrm{m}^{3}$ & 36608.0 & 36472.2 & 36668.7 & 36600.4 & 0.02 \\
\hline
\end{tabular}

It is interesting to note that for the choice of fuels coupled with the density and the blending fraction, the difference in volumetric calorific between Diesel and Blend is negligible while on mass basis the difference is pegged at $2 \%$. As such, hypothetically, purely on calorific value basis, the peak de-rating the engine is expected to experience should be around $2 \%$. Graphene, in the quantity of $50 \mathrm{mg} / \mathrm{litre}$ is added to the blend and that fuel is designated as B20G. The choice of $50 \mathrm{mg} /$ litre is based on the work by El-Sessy et al [10] where in a parametric analysis of Graphene quantity 
for different blends, $50 \mathrm{mg} / \mathrm{litre}$ has been reported to have generated the best results. The rotten coconut batch and the extracted oil are shown in figure 2.

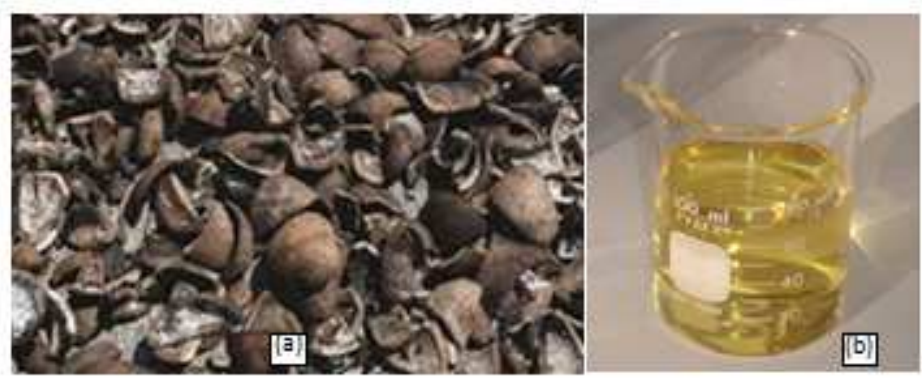

Figure 2: Rotten Coconut Pile (a) and Extracted Oil (b).

\subsection{Investigation Methodology}

Experiments are carried out for three fuel types of (a) Neat Diesel (b) Diesel + Bio-Oil blend and (c) Diesel + Bio-Oil blend with $50 \mathrm{mg} / \mathrm{l} \mathrm{Graphene} \mathrm{as} \mathrm{the} \mathrm{additive.} \mathrm{For} \mathrm{each} \mathrm{of} \mathrm{the} \mathrm{fuels,} \mathrm{full} \mathrm{load} \mathrm{range} \mathrm{parametric} \mathrm{analysis} \mathrm{is} \mathrm{carried} \mathrm{out} \mathrm{with}$ applied load varying in steps of 3,6,9 and $12 \mathrm{~kg}$ on the dynamometer. Considering the variation in the fuel viscosity, the injection pressure parametric analysis is also carried out at 175 bar, 200 bar and 225 bar. Neat Diesel operation provides the engine baseline data. The fuel consumption (volume of fuel consumed in fixed time) and in-cylinder pressure are the parameters of interest for the investigation with the engine speed and injection timing maintained at the optimal value corresponding to Diesel fuelled operation. For each fuel type, each cycle consisting of loading and unloading is repeated five times and the reported results are average of the data points at each load. In-cylinder data is also acquired on the engine and the presented crank angle - pressure trace presented is ensemble average of 250 consecutive cycles. The crank angle heat release profile is derived from the pressure crank angle profile by using the information in the first law analysis expression with the heat released evolving as the heat transfer across the boundary wall for a closed system [11].

\subsection{RESULTS AND DISCUSSIONS}

The results of the investigation are presented in subsections of (a) baseline Diesel performance with injection pressure parametric analysis (b) Blend performance with and without Graphene with injection pressure parametric analysis and (c) in-cylinder response characterization for the optimal performance case.

\subsection{Baseline Diesel Performance}

The baseline Diesel performance for the engine at the three injection pressures is presented in figure 3. Figure 3 (a) presents the variation of BSFC and efficiency with applied load while figure 3 (b) consolidates the peak load performance at the three injection pressures. The best performance is observed at 200 bar with slight deterioration of performance observed at 225 bar injection pressure. At 225 bar pressure the engine seems to be in the transition mode to overload conditions as is evident from slight increase in the supported power with concurrent increase in the specific fuel consumption. This particular trend is also evident from the trend line for the 225 bar injection pressure data points wherein the specific fuel consumption line tends to bottom out with tendency to rise up. 


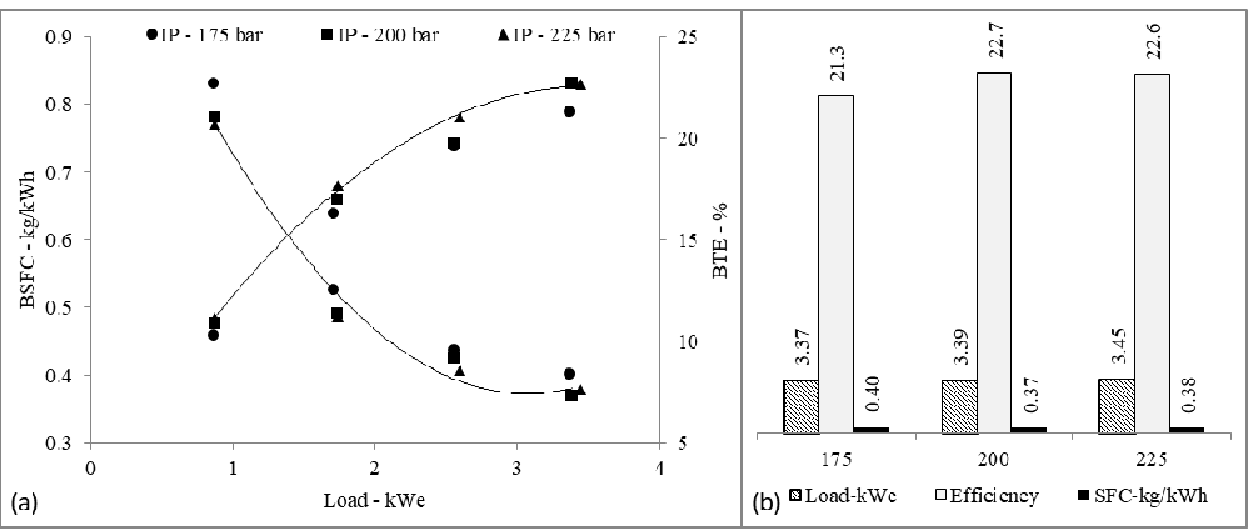

Figure 3: Baseline Diesel Performance with Injection Pressure Parametric Analysis.

\subsection{Blend Fuelled Operation}

Extending the analysis to engine operation with blended fuels, the variation of specific fuel consumption at different peak supported load for injection pressure parametric analysis is indicated in figure 4 (175 bar), figure 5 (200 bar) and figure 6 (225 bar) respectively.

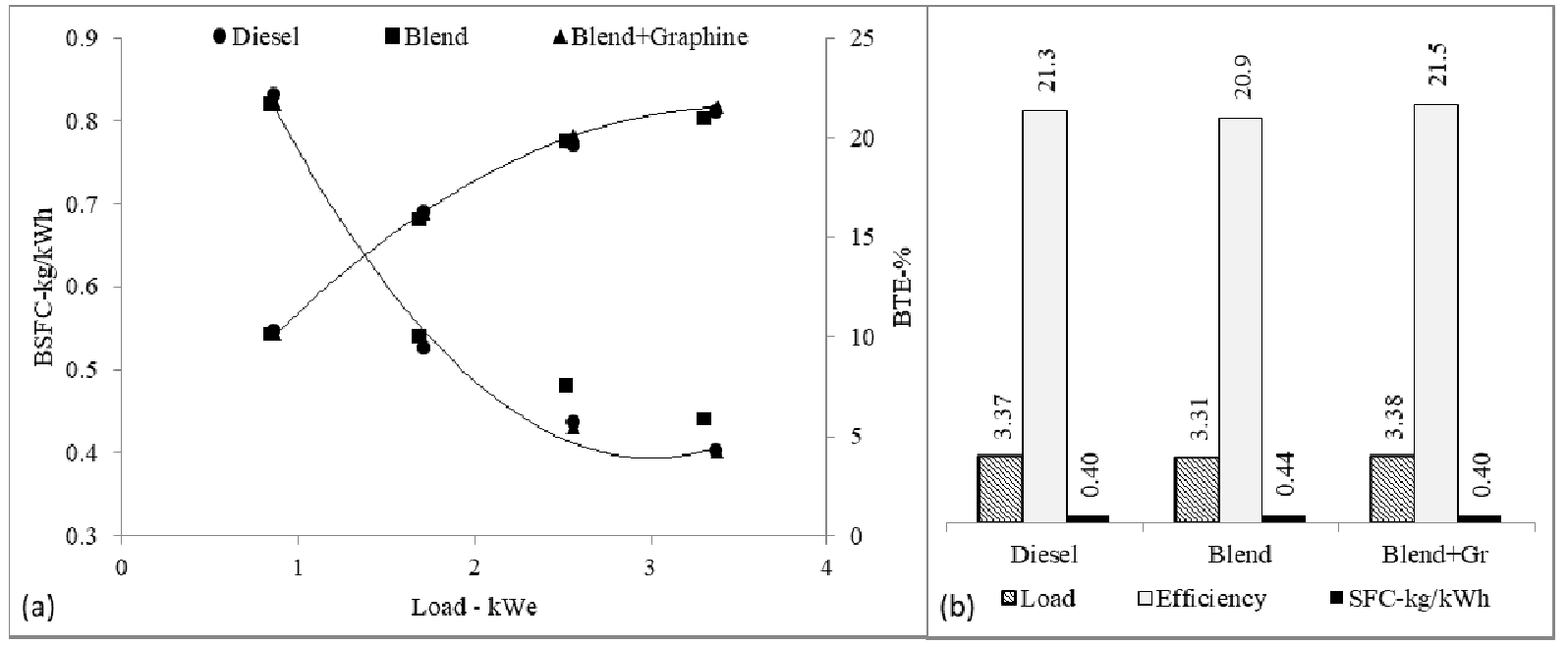

Figure 4: Load Parametric Variation for Three Fuel Types at 175 Bar Injection Pressure.

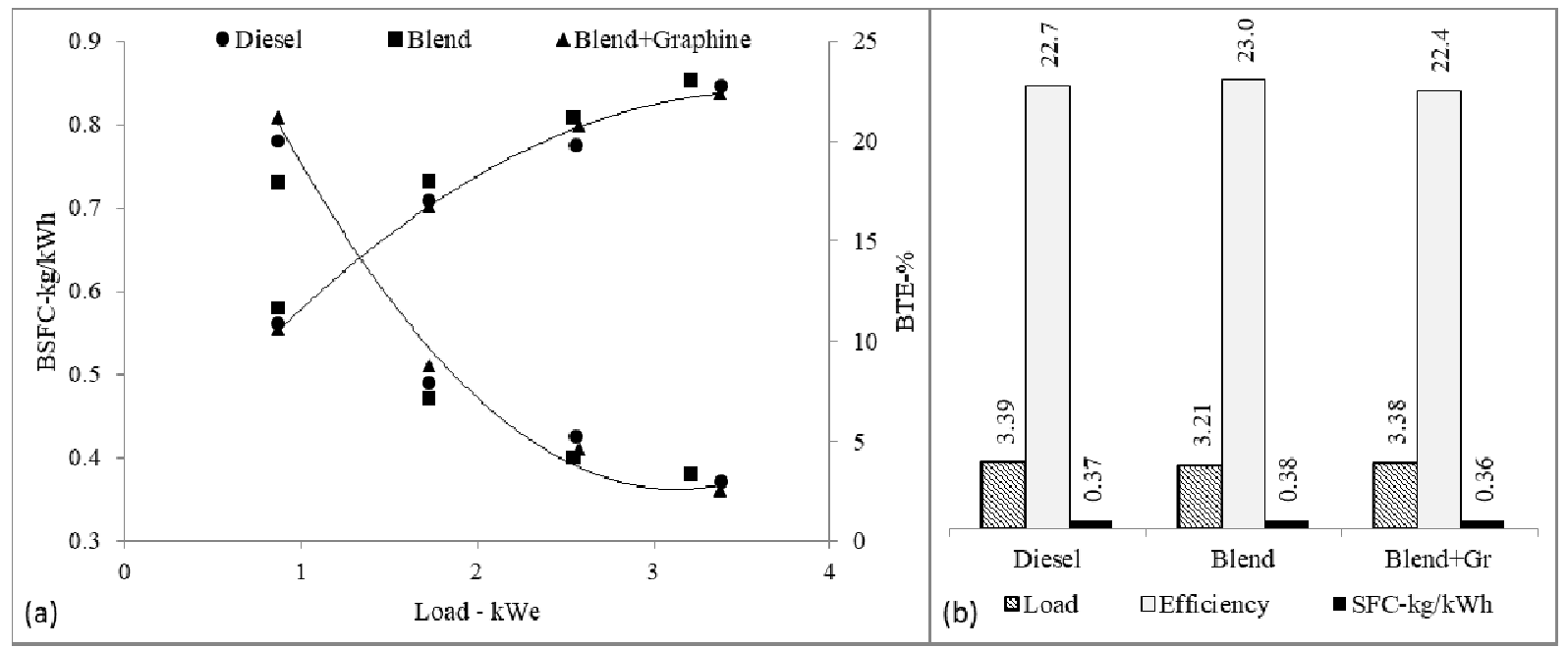

Figure 5: Load Parametric Variation for Three Fuel Types at 200 Bar Injection Pressure. 


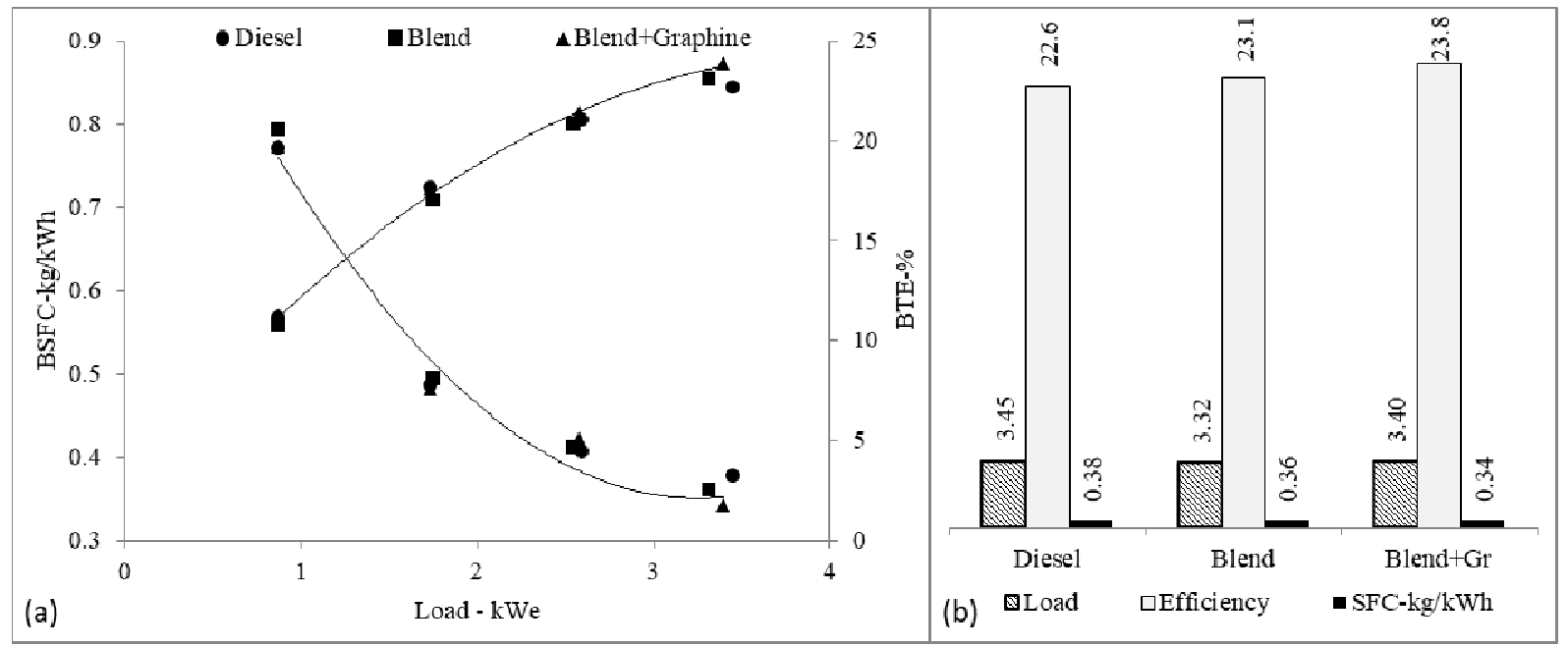

Figure 6: Load Parametric Variation for Three Fuel Types at 225 Bar Injection Pressure.

The analysis of engine response as presented in figures 4, 5 and 6, is presented in terms of (a) injection pressure parametric analysis for a particular fuel and (b) fuel type parametric analysis for a particular injection pressure.Section (b) of the figures present the peak load performance in terms of bar chart. The following key features are evident;

\section{Fuel Type Parametric Analysis}

- For any injection pressure, on moving from neat Diesel operation to blended operation, power de-rating is observed. This reduction in the peak supported load varied $1.8 \%$ and $5.2 \%$, with the maximum different being observed for 200 bar injection pressure.

- For each of the individual injection pressures, the peak supported load drops on moving from neat Diesel to Blended operation. On adding Graphene, a clear recovery is observed and the Blended operation very closely approaches the neat Diesel operation. In respect of the efficiency/specific fuel consumption also a general deterioration observed on moving from neat Diesel to Blend (with few exception) tends to show clear improvement on adding Graphene.

- Specifically in terms of quantified parameters, at 175 bar injection pressure, a near $10 \%$ increase in SFC is seen to completely neutralized on adding Graphene. The blended fuel with Graphene seems to perform similar to Diesel. At 200 bar, the SFC drops by almost 3\% for blended performance over neat Diesel but the interesting thing is on adding Graphene, the Blend + Graphene seems to indicate 3\% improvement over Diesel. This is a very interesting observation. Extending the analysis to 225 bar pressure, it is observed that the engine performance in terms of SFC seems to improve by about $5 \%$ on shifting from Diesel to Blend which on adding Graphene results in near $10 \%$ improvement over baseline Diesel performance.

\section{Injection Pressure Parametric Analysis}

- In case of diesel operation, the peak supported load increases with injection pressure but the fuel conversion efficiency is noted to maximize at 200 bar pressure. This is basically attributed to the fact that design injection pressure itself is at 200 bar.

- For Diesel - Bio Oil blend, the peak supported load injection pressure shifts from 200 bar to 225 bar. It is 
interesting to note that while the peak supported load is higher by about 3\%, the efficiency improvement is negligible at $0.5 \%$. It could possibly mean that the optimal injection time is somewhere between 200 and 225 bar injection pressure and at 225 bar, the performance is already on the decline but a little better than 200 bar operation. This is along expected lines considering that slightly higher viscosity of the blend demands enhanced injection pressure to ensure sufficient atomization.

- Operation at 225 bar pressure is of specific interest considering that a consistent improvement is observed from Diesel to Blend to Blend with Graphene.

\subsection{In-Cylinder Response Characterization}

The general performance of an engine is principally a manifestation of its in-cylinder response. Analysis of the incylinder response provides a detailed indication of the behaviour of the engine and all the full cycle based performance parameters can be completely addressed. In this regards, the peak load crank angle - pressure and crank angle - heat release rate profile for the 225 bar injection time case are compared in figure 7.

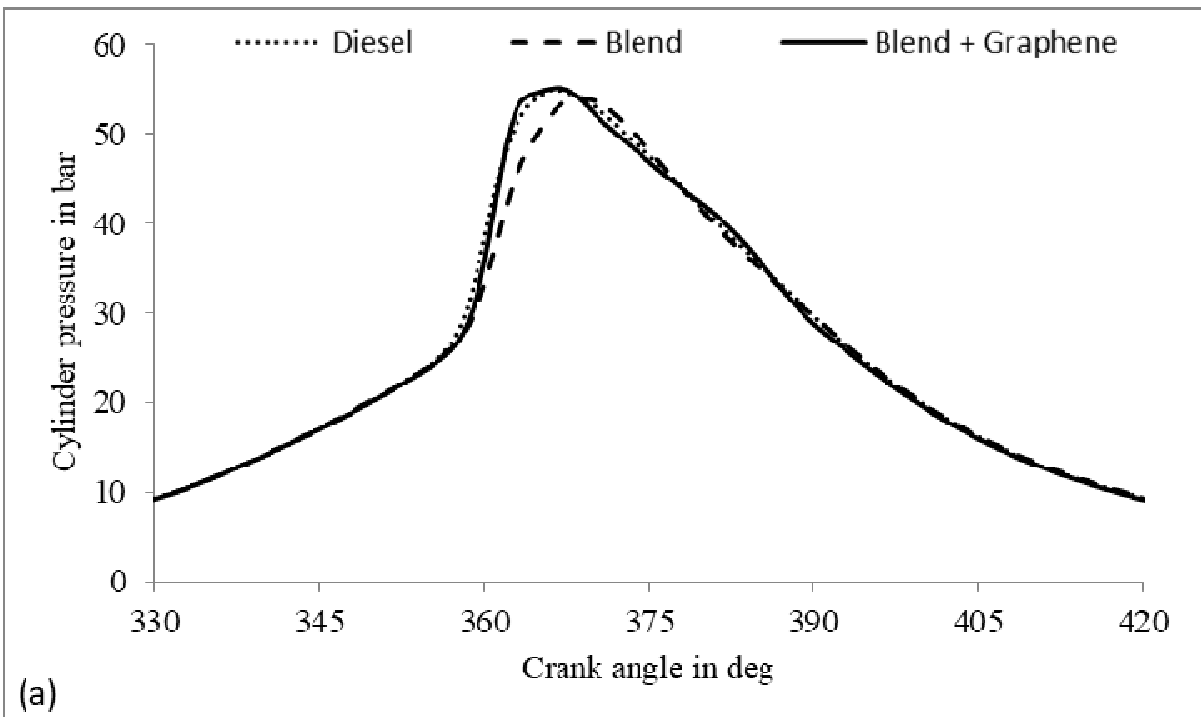

(a)

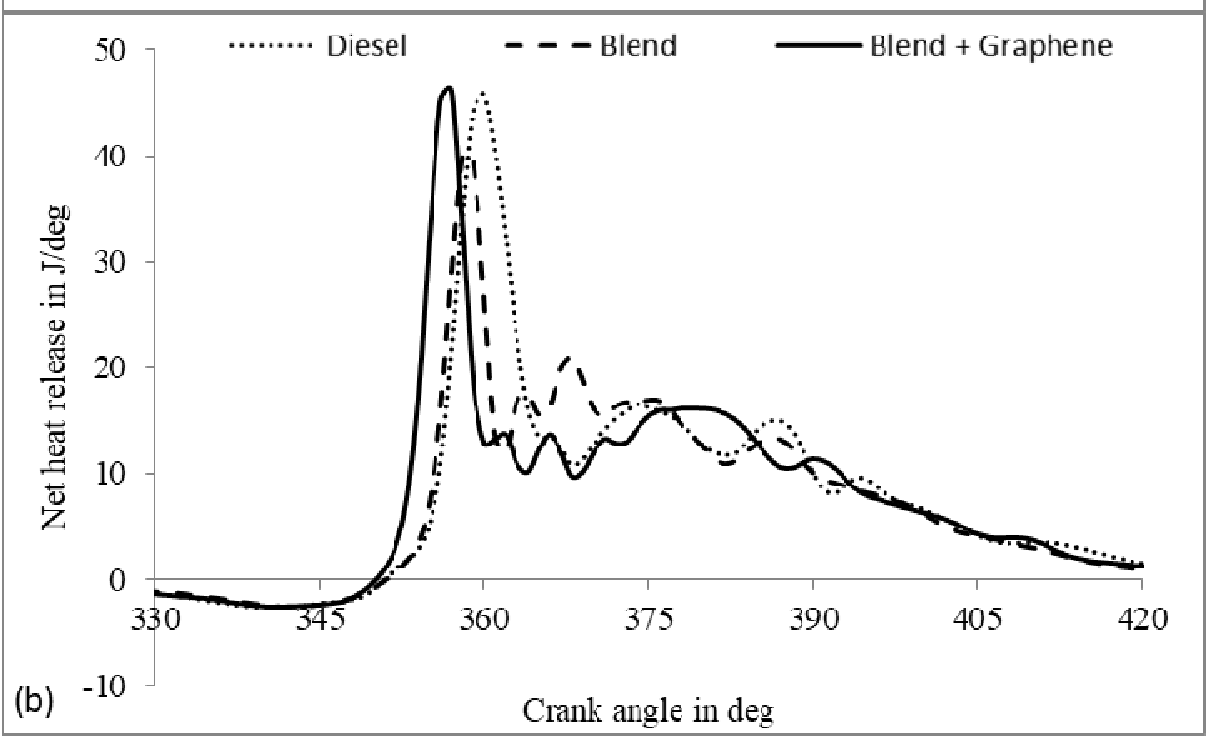

Figure 7: Crank Angle - in-Cylinder Pressure (a) and Crank Angle Heat Release Rate Profile (b) for 225 Bar Peak Load Case. 
It can be observed that on blending with diesel, a drop in the peak cylinder pressure is observed which is consistent considering that the energy content of the fuel itself is slightly lower. This is reflected in terms of the peak supported load also. The peak heat release rate being advanced as compared to Diesel is slightly surprising considering that the belnd should ideally be having higher ignition delay. This indicates a need for further investigating the properties of rotten coconut oil. On adding Graphene, a significant improvement in the heat release rate is observed as evident from the heat release rate profile and consequently the peak pressure profile seems to kind of overlap the Diesel profile. The improvement in the heat release rate is attributed to the acceleration of the combustion process on addition of Graphene [12]. The acceleration itself is primarily attributed to the rather large surface area to volume ratio of the Graphene which tends to substantially promote heat transfer [13] between the particles and the fuel droplets resulting in increased rate of combustion. Basically the Graphene particles are playing the role of turbulence in terms of enhancing the evaporation rate [14].

\subsection{CONCLUSIONS}

Summarizing the observations, addition of Graphene to Cotton seed oil - Rotten coconut oil - Diesel blend has resulted in measurable improvement in the performance, particularly at higher injection pressures. It is of interest to note that the frame performance of is near completely recovered on the addition of Graphene clearing the pathway for initiating a detailed analysis of the identified blend. From the current analysis, the reduction of neat Diesel to the extent of $20 \%$ and with it the extent of carbon foot print is clearly evident. It further establishes the potential of biologically degraded food items to produce bio-oils.

\subsection{REFERENCES}

1. Thuiller, W., et. al., (2019).Uncertainty in ensembles of global biodiversity scenarios. Nature Communications, 10(1), 1-9.

2. Li, B. et. al., (2017). Combustion and emission characteristics of diesel engine fueled with biodiesel/PODE blends. Applied Energy, 206, 425-431.

3. Khond, V. W., et. at., (2016). Effect of nanofluid additives on performances and emissions of emulsified diesel and biodiesel fueled stationary CI engine: A comprehensive review. Renewable and Sustainable Energy Reviews, 59, 1338-1348.

4. Balandin, A. A. (2011). Thermal properties of graphene and nanostructured carbon materials.Nature materials, 10(8), 569581.

5. Rasheed, A. K., et. a;., (2016). Heat transfer and tribological performance of graphene nanolubricant in an internal combustion engine. Tribology International, 103, 504-515.

6. Joshi, MP, and SS Thipse. "An Evaluation of Algae Biofuel as the Next Generation Alternative Fuel and its Effects on Engine Characteristics: A Review."International Journal of Mechanical and Production Engineering Research and Development (IJMPERD) 9. 1, Feb 2019, 435-440

7. Heidari-Maleni, A., et. al., (2020). Performance improvement and exhaust emissions reduction in diesel engine through the use of graphene quantum dot (GQD) nanoparticles and ethanol-biodiesel blends. Fuel, 267, 117116.

8. Paramashivaiah, B. M., et. al., (2018).Studies on effect of graphene nanoparticles addition in different levels with simarouba biodiesel and diesel blends on performance, combustion and emission characteristics of CI engine.Arabian Journal for Science and Engineering, 43(9), 4793-4801. 
9. Hoseini, S. S., et. al., (2020). Performance and emission characteristics of a CI engine using graphene oxide (GO) nanoparticles additives in biodiesel-diesel blends. Renewable Energy, 145, 458-465.

10. Soudagar, M. E. M., et. al., (2019). The effects of graphene oxide nanoparticle additive stably dispersed in dairy scum oil biodiesel-diesel fuel blend on CI engine: performance, emission and combustion characteristics. Fuel, 257, 116015.

11. Sulochana, Gaddala, and SK Bhatti. "Performance and Emission Characteristics of a Twin Cylinder Diesel Engine Blended Biodiesel with Nano Aditives using Response Surface Methodology. "International Journal of Mechanical and Production Engineering Research and Development (IJMPERD) 8. 3, Jun 2018, 635-646

12. EL-Seesy, et. al., (2018). Performance, combustion, and emission characteristics of a diesel engine fueled with Jatropha methyl ester and graphene oxide additives. Energy Conversion and Management, 166, 674-686.

13. Shivapuji, A. M., et. at., (2013).Experiments and zero D modeling studies using specific Wiebe coefficients for producer gas as fuel in spark-ignited engines. Proceedings of the IMechE, Part C: Journal of Mechanical Engineering Science, 227(3), 504-519.

14. Darji, Sunny K., Jigar K. Parmar, and Gajendra R. Patel."Energy Storage System with Multilevel Inverter for Distributed Grid Application. "International Journal of Electrical and Electronics Engineering (IJEEE) 7. 3, Apr - May 2018, 1-16

15. El-Seesy, A. I., et. al., (2020). Investigation the effect of adding graphene oxide into diesel/higher alcohols blends on a diesel engine performance. International Journal of Green Energy, 17(3), 233-253.

16. Arzani, H. K., et. al., (2015). Experimental and numerical investigation of thermophysical properties, heat transfer and pressure drop of covalent and noncovalent functionalized graphene nanoplatelet-based water nanofluids in an annular heat exchanger. International Communications in Heat and Mass Transfer, 68, 267-275.

17. Brandl, F., et. al., (1979).Turbulent air flow in the combustion bowl of a DI diesel engine and its effect on engine performance. SAE Transactions, 172-199. 